\title{
Can hospital accreditation enhance patient experience? Longitudinal evidence from a Hong Kong hospital patient experience survey
}

Ellie Bostwick Andres ${ }^{*} \mathbb{D}$, Wen Song, Wei Song and Janice Mary Johnston

\begin{abstract}
Background: Hospital accreditation is expected to improve health care quality and patient satisfaction. However, little and conflicting evidence is currently available to support its effect on patient outcomes, particularly patient experience. Hong Kong recently launched a pilot programme to test an infrastructure for accreditation of both private and public hospitals with the Australian Council on Healthcare Standards. This study aims to evaluate the longitudinal impact of hospital accreditation on patient experience in a publicly-funded university teaching hospital in Hong Kong.
\end{abstract}

Methods: Three cross-sectional surveys were conducted at three time points: 9 months pre- accreditation as baseline (T1), three (T2) and fifteen months (T3) post-accreditation. Acute care inpatients aged 18 to 80 were recruited on the second day of hospital admission to complete the Picker Patient Experience Questionnaire-15 (PPE-15). Baseline data was first compared to the 2005 Hong Kong average for public hospitals using t-tests. Data was then analyzed using ANOVA and multiple linear regression to evaluate differences across the three crosssections and examine the effect of accreditation over time while controlling for covariates.

Results: 3083 patients $(T 1=896, T 2=1093, T 3=1094)$ completed the survey for a response rate of 83.5, 86.1, and $83.8 \%$, respectively. The hospital baseline domain and summary patient experience scores differed from the Hong Kong public hospital average obtained from the 2005 Thematic Household Survey. All domain and summary patient experience scores declined (improved) over the study period (T1 to T3). The multiple regression results confirmed the time point score comparisons with declining (improving) parameter estimates for T2 and T3 for all domain and summary scores except the 'continuity and transition' domain, for which the declining coefficient was only significant at T3.

Conclusions: While hospital accreditation has not been shown to improve patient outcomes, this study suggests the accreditation exercise may enhance patient experience. Moreover, it suggests the quality improvement initiatives associated with accreditation may address areas of concern emphasized by Hong Kong patients, such as involvement in care and emotional support from providers.

Keywords: External quality assessment, Patient satisfaction, Hospital medicine, Accreditation

\footnotetext{
* Correspondence: eandres@hku.hk

Univeristy of Hong Kong, School of Public Health, Patrick Manson Building,

(North Wing), 7 Sassoon Road, Pokfulam, Hong Kong
}

(c) The Author(s). 2019 Open Access This article is distributed under the terms of the Creative Commons Attribution 4.0 International License (http://creativecommons.org/licenses/by/4.0/), which permits unrestricted use, distribution, and reproduction in any medium, provided you give appropriate credit to the original author(s) and the source, provide a link to the Creative Commons license, and indicate if changes were made. The Creative Commons Public Domain Dedication waiver (http://creativecommons.org/publicdomain/zero/1.0/) applies to the data made available in this article, unless otherwise stated. 


\section{Background}

Patient experience is recognized as an essential indicator of health care quality, alongside clinical effectiveness and patient safety [1-3]. Regular collection of patient experience data allows for identification of strengths and weaknesses in health care delivery and drives quality improvement [4-6]. Public and private insurers in some countries and international accrediting bodies consider hospital performance on patient experience metrics in providing payment and certification $[7,8]$.

Accreditation is a practice of systematically assessing hospital performance against accepted quality standards [9]. Successful certification of accreditation signals to patients and other stakeholders that a minimum standard has been achieved [10]. This approach to quality improvement is predicated on the expectation that the accreditation exercise leads to improvement in clinical governance and quality of care $[11,12]$. However, the impact of accreditation is difficult to evaluate and limited evidence exists supporting its effect on patient outcomes $[13,14]$.

Longitudinal comparisons of inpatient experience could provide valuable inter-organisational evaluations of quality improvement initiatives, such as accreditation. Patient experience, determined by the quality of information, communication and organisation within the healthcare setting could serve as a proxy metric for the impact of accreditation, as it informs the structure, processes and outcomes of care $[15,16]$. However, little and conflicting empirical evidence is currently available to support the assumption that hospital accreditation leads to improved patient experience. One review of the accreditation literature found no significant relationship between accreditation and patient satisfaction among 20 included studies, and identified only two studies seeking to evaluate aspects of patient experience before and after accreditation with limited effect [17].

The Hong Kong public hospital system recently launched a pilot programme to test an infrastructure for accreditation of both private and public hospitals with the Australian Council on Healthcare Standards (ACHS) [18]. This study seeks to assess the longitudinal impact of hospital accreditation on patient experience through three cross-sectional evaluations conducted at a hospital participating in the pilot accreditation programme in Hong Kong.

\section{Methods}

This study was part of a prospective mixed methods evaluation of the impact of accreditation on hospital quality, patient experience and organisational culture conducted in a large, publicly funded, university teaching hospital in Hong Kong. The hospital's accreditation process began with a gap analysis based on ACHS standards and subsequent quality improvement initiatives to address identified gaps as described in detail elsewhere [18]. The hospital's quality improvement activities included efforts to address hospital-wide issues, such as improving coordination, reporting and integration as well as specific department and procedure-level gaps. The current paper presents findings from the patient experience survey evaluating the effect of accreditation on care experience.

\section{Study subjects}

Acute care inpatients aged 18 to 80 were recruited to participate in the survey on the second day of their hospital admission at three time points corresponding with accreditation: 9 months pre-accreditation (T1) as baseline, three (T2) and 15 (T3) months post-accreditation. Hospital admission and discharge staff identified eligible patients from the daily hospital admission records and prepared rosters for the research team. Patients were excluded if they were admitted to the intensive care unit, Accident and Emergency observation, isolation, labour, private, psychiatric or custodial wards, had a psychiatric diagnosis, were in poor physical status, or were unable to communicate in Cantonese, Mandarin or English. Ward nursing staff confirmed patient eligibility.

\section{Survey instrument}

The widely used and internationally validated Picker Patient Experience Questionnaire-15 (PPE-15) was selected to evaluate participants' experience with their recent inpatient episode. The PPE-15 measures seven aspects of inpatient experience: information and education, coordination of care, physical comfort, emotional support, respect for patient preferences, involvement of family and friends and community and transition [19]. The PPE-15 was used for the first examination of self-reported inpatient experience in Hong Kong, conducted as part of the 2005 Thematic Household Survey [3]. The 2005 data is used as a reference for this study.

Seven additional items collected patient demographic information, including education level, marital status, smoking and drinking history, self-perceived health, private health insurance coverage and medical benefits. The questionnaire was administered in Cantonese, English or Mandarin based on patient preference. Survey items were translated and back-translated by research staff and pilot tested to ensure accuracy and comprehension.

\section{Procedure}

The same procedure was followed for each of the three data collection periods in January-March 2010, 2011, and 2012. Research staff approached eligible patients in the ward and invited them to participate. Upon agreement, research staff obtained patient consent, contact 
telephone numbers and preferred time for follow up phone call. Trained research staff then contacted recruited patients one-week post discharge via telephone and if unable to reach, conducted up to five additional attempts at various times of day to increase the response rate. Response rate was calculated as the number of survey respondents over the number of patients who consented to participate and were contacted by telephone.

A unique study identification number (USI) was generated for recruited patients and linked to their corresponding Hospital Number $(\mathrm{HN})$. $\mathrm{HN}$ is a per case (admission) hospital identification number. For each recruited patient, the Admission and Discharge office provided admission ward, discharge diagnoses (ICD-9-CM; up to 15), total number of hospital admissions in the preceding year, and length of stay information. All data analysis used de-identified data. All identifying information was excluded prior to analysis by employing USI numbers as the sole form of identification in the dataset. To ensure there was no risk of personal data being identified by name, all relevant information was encrypted and stored in a separate file, with the master linking file kept in a data safe.

\section{Scoring and analysis}

Based on the previously validated PPE scoring scheme, we coded each item dichotomously to indicate the presence or absence of a problem (See Fig. 1 for sample questions and scoring). "Problems" are aspects of the health care experience patients indicated could be improved. Summary scores were calculated as the 'number of items identifying a problem' over the 'number of items answered by the patient' on a scale of zero to 100 , with zero indicating no problem and 100 indicating many problems. PPE-15 summary, domain and item scores were calculated for each collection period (T1, T2 and T3).

We first compared baseline (T1) PPE-15 scores for the study hospital to the Hong Kong public hospital scores obtained through the 2005 Thematic Household Survey

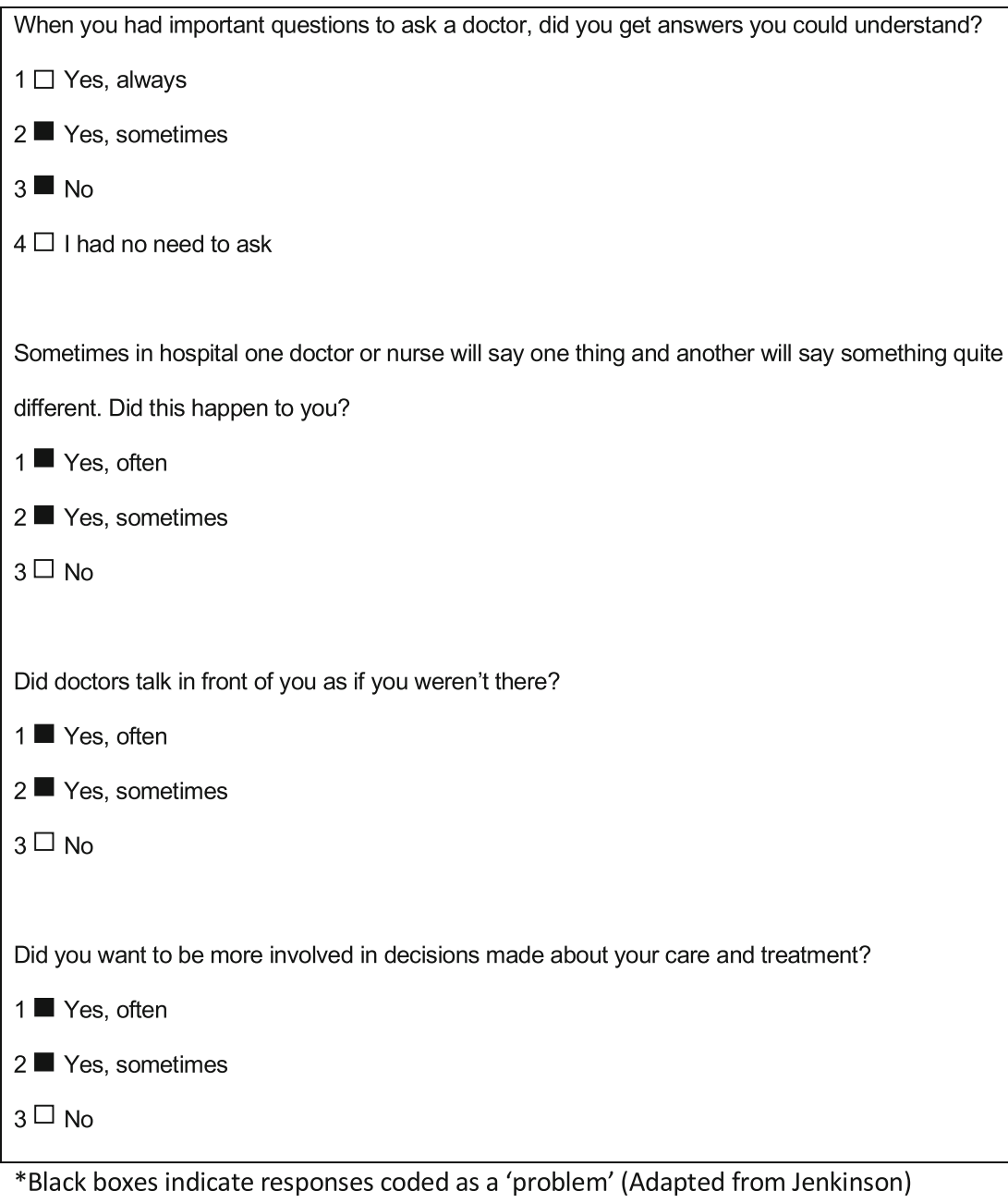

Fig. 1 PPE-15 Sample Questions and Dichotomous Scoring 
(THS) [3]. The THS is a series of regular, repeated cross-sectional household surveys sampling the entire land-based Hong Kong population and covering a wide spectrum of social issues. Each survey usually focuses on two substantive policy subjects. The 2005 THS was the first to include patient experience as one of the survey sections, specifically inquiring about the most recent hospital admission in the 12 months prior to the survey. Hence, the survey items were only relevant for respondents with a recent admission and the recall period was for the entire year rather than 1 week as in our study data. We used t-tests to compare our hospital baseline scores to the 2005 Hong Kong average for public hospitals.

We then used ANOVA to evaluate differences in PPE scores across the three cross-sections with the Bonferroni post-hoc test for pairwise comparisons. Finally, we used multiple linear regression analysis with time period as the predictor variable and patient experience scores as the outcome variables to examine the effect of accreditation over time. Covariates included patient age, gender, self-reported education level, marital status, selfreported health status, smoking and alcohol use, insurance status, medical benefit status, length of stay, prior admissions and number of comorbidities. We also conducted sensitivity analyses for patients with lengths of stay ( $>4$ days) or number of prior admissions ( $>1$ prior admission) above the median since the ranges varied widely. All data analyses were conducted in STATA 13. A priori significance level of 0.05 was used for all statistical tests.
The study was approved by the Institutional Review Board of the institution and study hospital involved.

\section{Results}

Hospital staff identified 7114 patients $(\mathrm{T} 1=2770, \mathrm{~T} 2=$ 2082 , T3 $=2262$ ) from the admission records meeting study eligibility criteria. Ward nurses further excluded 2556 patients they were unable to locate $(\mathrm{T} 1=722, \mathrm{~T} 2=$ 291 , T3 $=358$ ), or who were unable to communicate or in too poor physical status $(\mathrm{T} 1=526, \mathrm{~T} 2=286, \mathrm{~T} 3=$ 373). Finally, 739 patients declined to participate ( $\mathrm{T} 1=$ $389, \mathrm{~T} 2=161, \mathrm{~T} 3=189)$, leaving $3819(\mathrm{~T} 1=1133, \mathrm{~T} 2=$ 1344, T3 =1342) patients who gave consent for telephone follow-up (See Fig. 2). Following discharge, 3083 patients $(\mathrm{T} 1=896, \mathrm{~T} 2=1093, \mathrm{~T} 3=1094)$ completed the survey for a response rate of $83.5,86.1$, and $83.8 \%$, respectively.

Participants did not differ by socio-demographic characteristics across the three time points (See Table 1). However, self-reported health characteristics varied by time point. T1 participants were less likely to have prior admissions and comorbidities than T2 and T3 participants, while T3 participants reported better perceived health than $\mathrm{T} 1$ and $\mathrm{T} 2$ participants.

\section{Patient experience scores}

The hospital baseline PPE-15 scores were all significantly different from the Hong Kong public hospital average $(p<.05)$ (Table 2). Hospital baseline scores for the 'information and education,' 'physical comfort,' and 'continuity and transition' domains were higher (worse),
9 months pre-accreditation (T1)

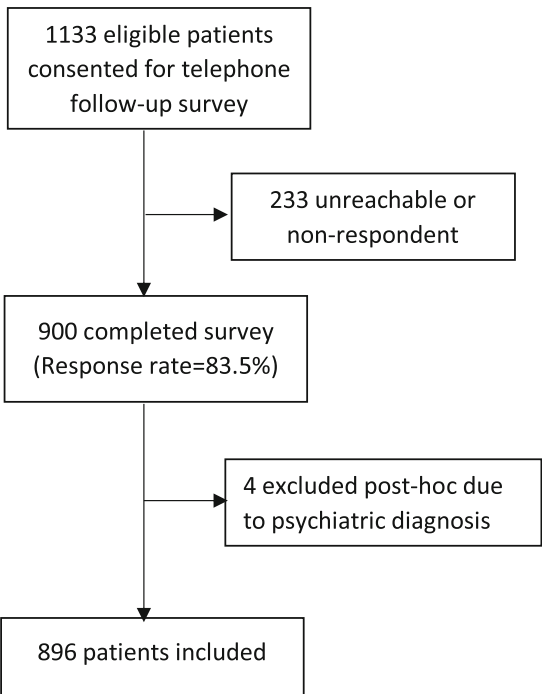

3 months post-accreditation (T2)

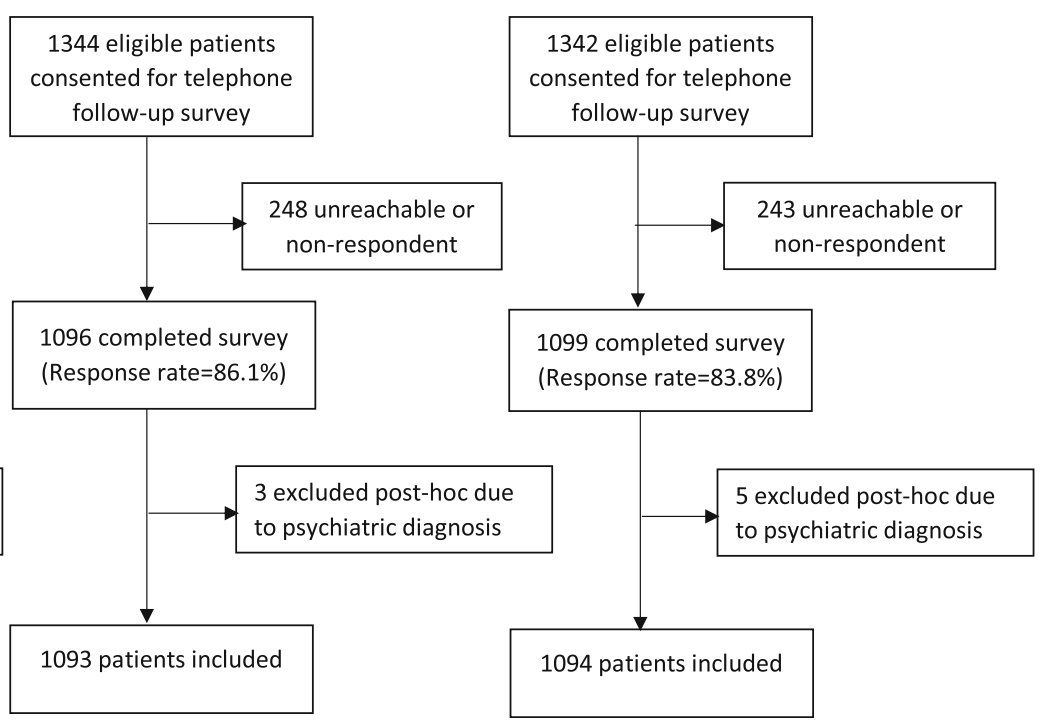

Fig. 2 Patient Recruitment Flow Chart 
Table 1 Descriptive Statistics

\begin{tabular}{|c|c|c|c|c|}
\hline \multirow[t]{2}{*}{ Category } & $\mathrm{T} 1(N=896)$ & $\mathrm{T} 2(N=1093)$ & T3 $(N=1094)$ & \multirow[t]{2}{*}{$p$-value ${ }^{1}$} \\
\hline & N (\%) & N (\%) & N (\%) & \\
\hline Sex & & & & 0.19 \\
\hline Male & $477(53.24)$ & $582(53.25)$ & $545(49.82)$ & \\
\hline Female & 419 (46.76) & $511(46.75)$ & $549(50.18)$ & \\
\hline Age & & & & 0.50 \\
\hline $18-24$ & $45(5.02)$ & $60(5.49)$ & $52(4.75)$ & \\
\hline $25-34$ & $76(8.48)$ & 95 (8.69) & $76(6.95)$ & \\
\hline $35-44$ & $131(14.62)$ & $128(11.71)$ & $140(12.80)$ & \\
\hline $45-54$ & $173(19.31)$ & $211(19.30)$ & $234(21.39)$ & \\
\hline $55-64$ & $224(25.00)$ & $278(25.43)$ & $263(24.04)$ & \\
\hline $65-80$ & $247(27.57)$ & $321(29.37)$ & $329(30.07)$ & \\
\hline Median & 56 & 56 & 56 & 0.78 \\
\hline Education Level & & & & 0.86 \\
\hline Primary or below & $283(31.62)$ & 349 (32.02) & $333(30.75)$ & \\
\hline Secondary & $422(47.15)$ & $521(47.80)$ & $535(49.4)$ & \\
\hline Tertiary & $190(21.23)$ & $220(20.18)$ & $215(19.85)$ & \\
\hline Marital Status & & & & 0.86 \\
\hline Never married & $182(20.31)$ & $236(21.71)$ & 215 (19.93) & \\
\hline Married & $602(67.19)$ & $721(66.33)$ & $726(67.28)$ & \\
\hline Widowed/Separated & $112(12.50)$ & $130(11.96)$ & $138(12.79)$ & \\
\hline Self-Perceived Health & & & & 0.00 \\
\hline Good/Nery good/ Excellent & $283(31.76)$ & $334(30.64)$ & 439 (40.72) & \\
\hline Fair / poor & $608(68.24)$ & 756 (69.36) & $639(59.28)$ & \\
\hline \multicolumn{5}{|l|}{ Length of stay } \\
\hline Median (Range) & $4(2-46)$ & $4(2-52)$ & $4(2-60)$ & 0.05 \\
\hline Prior admission in last 12 months & & & & 0.00 \\
\hline 0 & $357(39.84)$ & $328(30.01)$ & 319 (29.16) & \\
\hline 1 & $174(19.42)$ & $231(21.13)$ & $239(21.85)$ & \\
\hline$\geq 2$ & 365 (40.74) & $534(48.86)$ & $536(48.99)$ & \\
\hline Median (Range) & $1(0-139)$ & $1(0-156)$ & $1(0-157)$ & 0.00 \\
\hline Number of comorbidities & & & & 0.00 \\
\hline 0 & $297(33.15)$ & $345(31.56)$ & $309(28.24)$ & \\
\hline 1 & $276(30.80)$ & $256(23.42)$ & $287(26.23)$ & \\
\hline$\geq 2$ & $323(36.05)$ & $492(45.01)$ & $498(45.52)$ & \\
\hline Median (Range) & $1(0-11)$ & $1(0-14)$ & $1(0-13)$ & 0.00 \\
\hline
\end{tabular}

while 'coordination of care', 'emotional support,' 'respect for patient preferences,' and 'involvement of family and friends' domains were significantly lower (better) than the Hong Kong public hospital average.

Overall, the PPE-15 summary scores and domain scores declined significantly (improved) over the study period (T1 to T3) (Table 2). Between T1 and T2, all domain scores declined except for the 'continuity and transition' domain, reflecting high scores for two items related to medication information. Between $\mathrm{T} 2$ and T3, the 'continuity and transition' domain showed significant improvement, while other domains continued to improve (i.e. 'care coordination', 'emotional support', 'respect for patient preferences' and 'involvement of family and friends') or hold steady (i.e. 'information and education' and 'physical comfort').

The multiple regression results (Table 3) confirmed the time point score comparisons. The T2 and T3 
Table 2 Hong Kong Public Hospital 2005 Average and Study Hospital PPE-15 Summary, Domain and Item Scores

\begin{tabular}{|c|c|c|c|c|c|}
\hline \multirow[t]{2}{*}{ PPE-15 Items } & $\begin{array}{l}2005 \text { Hong Kong } \\
\text { Public Hospital } \\
(N=2901)\end{array}$ & $\mathrm{T} 1(\mathrm{~N}=896)$ & $\mathrm{T} 2(\mathrm{~N}=1093)$ & $\mathrm{T} 3(\mathrm{~N}=1094)$ & \multirow[t]{2}{*}{$p$-value } \\
\hline & $\begin{array}{l}\text { Weighted\% } \\
(95 \% \mathrm{Cl})\end{array}$ & Mean $(95 \% \mathrm{Cl})$ & Mean $(95 \% \mathrm{Cl})$ & Mean $(95 \% \mathrm{Cl})$ & \\
\hline Information and education & $37.6(35.0-40.2)$ & $40.0(37.3-42.6)$ & $28.0(25.8-30.3)$ & $28.3(26.0-30.6)$ & 0.000 \\
\hline Nurses' answer to questions not clear & $39.2(36.4-42.1)$ & $41.4(38.2-44.6)$ & $25.9(23.3-28.5)$ & $29.0(26.3-31.7)$ & 0.000 \\
\hline Doctors' answers to questions not clear & $34.8(32.0-37.7)$ & $38.5(35.3-41.7)$ & $30.2(27.5-32.9)$ & $27.6(25.0-30.3)$ & 0.000 \\
\hline \multicolumn{6}{|l|}{ Coordination of care } \\
\hline Staff gave conflicting information & $30.8(28.0-33.7)$ & $30.3(27.3-33.3)$ & $24.3(21.8-26.9)$ & $17.7(15.5-20.0)$ & 0.000 \\
\hline \multicolumn{6}{|l|}{ Physical comfort } \\
\hline Staff did not do enough to control pain & $22.7(20.2-25.3)$ & $37.5(33.7-41.3)$ & $30.6(26.8-34.3)$ & $29.0(25.4-32.6)$ & 0.003 \\
\hline Emotional support & $51.6(49.3-53.9)$ & $46.7(44.2-49.2)$ & $36.7(34.5-38.8)$ & $32.1(30.0-34.1)$ & 0.000 \\
\hline Nurses did not discuss anxiety or fears & $53.9(50.9-56.9)$ & $49.3(46.0-52.6)$ & $37.8(34.9-40.7)$ & $36.9(34.0-39.8)$ & 0.000 \\
\hline Doctor did not discuss anxiety or fears & $49.6(46.6-52.6)$ & $41.1(37.8-44.3)$ & $28.4(25.7-31.1)$ & $30.1(27.4-32.8)$ & 0.000 \\
\hline Difficult to find someone to talk to about concerns & $51.3(48.3-54.3)$ & $49.7(46.6-52.9)$ & $43.6(40.7-46.6)$ & $29.0(26.3-31.7)$ & 0.000 \\
\hline Respect for patient preferences & $51.9(50.3-53.5)$ & $38.9(37.0-40.8)$ & $31.3(29.6-32.8)$ & $20.5(19.0-22.1)$ & 0.000 \\
\hline $\begin{array}{l}\text { Not sufficiently involved in decisions about treatment and } \\
\text { care }\end{array}$ & $89.0(86.8-91.0)$ & $65.5(62.4-68.6)$ & $55.0(52.0-57.9)$ & $32.6(29.8-35.4)$ & 0.000 \\
\hline Not always treated with respect and dignity & $37.7(34.8-40.6)$ & $32.2(29.1-35.2)$ & $25.4(22.8-28.0)$ & $20.9(18.5-23.3)$ & 0.000 \\
\hline Doctors sometimes talked as if I was not there & $30.0(27.3-32.8)$ & $19.0(16.4-21.6)$ & $13.5(11.4-15.5)$ & $7.8(6.2-9.4)$ & 0.000 \\
\hline Involvement of family and friends & $48.6(46.1-51.2)$ & $46.6(44.0-49.3)$ & $35.2(32.9-37.4)$ & $34.3(32.3-36.4)$ & 0.000 \\
\hline Family did not get opportunity to talk to doctor & $50.7(47.7-53.6)$ & $39.7(36.5-42.9)$ & $23.6(21.1-26.1)$ & $21.7(19.2-24.1)$ & 0.000 \\
\hline Family not given information needed to help recovery & $46.4(43.5-49.4)$ & $53.4(50.1-56.7)$ & $46.6(43.6-49.5)$ & $47.5(44.5-50.5)$ & 0.005 \\
\hline Continuity and transition & $28.8(26.6-31.1)$ & $43.3(41.0-45.5)$ & $42.2(40.2-44.2)$ & $36.3(34.4-38.1)$ & 0.000 \\
\hline Not told about danger signals to look for at home & $30.0(27.3-32.8)$ & $56.5(53.4-59.7)$ & $50.6(47.7-53.6)$ & $49.7(46.7-52.7)$ & 0.006 \\
\hline Purpose of medicines not explained & $28.5(25.9-31.3)$ & $21.6(18.9-24.3)$ & $19.4(17.1-21.8)$ & $11.4(9.5-13.3)$ & 0.000 \\
\hline Not told about medication side effects & $24.3(21.7-27.0)$ & $54.9(51.3-58.4)$ & $60.3(57.2-63.4)$ & $51.2(47.9-54.4)$ & 0.000 \\
\hline Summary Score & $41.8(40.3-43.3)$ & $41.9(40.3-43.4)$ & $34.1(32.8-35.4)$ & $29.1(27.9-30.3)$ & 0.000 \\
\hline
\end{tabular}

Notes: Higher scores correspond with less satisfied patients. T1 = Baseline 9 months pre-accreditation survey; T2 = 3 months post-accreditation survey; T3 = 15 months post-accreditation survey

${ }^{1}$ Chan SK, Wong IO, Tin KY, Fung A, Johnston JM, Leung GM. Satisfaction with inpatient care in a population-based Hong Kong Chinese sample. Quality \& safety in health care. 2010;19(3):173-81

${ }^{2}$ ANOVA comparison of 3 time points

The boldface items indicate domains and domain scores

parameter estimates were declining (improving) for PPE15 summary scores and all domain scores except for the 'continuity and transition' domain, for which the declining coefficient was only significant at $\mathrm{T} 3$. When adjusted for all covariates, the multiple regression parameter estimates were similar to the unadjusted estimates. Likewise, the sensitivity analyses confirmed similar findings among patients with multiple prior admissions and longer lengths of stay ( $>4$ days) (data not shown). Patients with longer stays generally evaluated their experience more favourably (lower scores) than the full sample, while patients with multiple prior admissions indicated more problems. However, trends in patient experience scores among patients with longer stays and patients with multiple prior admissions were generally consistent with the full sample except for the 'physical comfort' domain, which while declining was not significant at T2 or T3 for patients with longer stays and T3 for patients with multiple prior admissions.

\section{Discussion}

To our knowledge, this is the first attempt to evaluate the effect of accreditation longitudinally using patient experience scores. Our findings indicate robust improvements in patient experience in the study hospital following accreditation with continued or sustained improvements at 15 months post-accreditation. These results provide initial support for the positive potential of the hospital accreditation exercise to enhance patient experience. 
Table 3 Multiple Regression with Time Point (Post-accreditation) as Predictor of PPE-15 Domain and Summary Scores

\begin{tabular}{|c|c|c|c|c|c|c|}
\hline \multirow[t]{2}{*}{ PPE-15 Domains } & & \multirow[t]{2}{*}{$\mathrm{T1}(\mathrm{N}=896)$} & \multicolumn{2}{|l|}{$\mathrm{T} 2(\mathrm{~N}=1093)$} & \multicolumn{2}{|l|}{ T3 $(\mathrm{N}=1094)$} \\
\hline & & & Parameter estimate $(95 \% \mathrm{Cl})$ & $p$-value & Parameter estimate $(95 \% \mathrm{Cl})$ & $p$-value \\
\hline \multirow[t]{2}{*}{ Information and education } & Adjusted & Ref. & $-11.9(-15.3,-8.5)$ & 0.000 & $-11.7(-15.1,-8.2)$ & 0.000 \\
\hline & & Ref. & $-12.3(-15.7,-8.8)$ & 0.000 & $-11.2(-14.7,-7.8)$ & 0.000 \\
\hline \multirow[t]{2}{*}{ Coordination of care } & Adjusted & Ref. & $-6.0(-9.7,-2.2)$ & 0.002 & $-12.6(-16.3,-8.8)$ & 0.000 \\
\hline & & Ref. & $-6.4(-10.2,-2.7)$ & 0.001 & $-11.9(-15.6,-8.1)$ & 0.000 \\
\hline \multirow[t]{2}{*}{ Physical comfort } & Adjusted & Ref. & $-6.9(-12.2,-16.6)$ & 0.010 & $-8.5(-13.7,-3.3)$ & 0.001 \\
\hline & & Ref. & $-8.2(-13.5,-2.9)$ & 0.002 & $-8.8(-14.1,-3.5)$ & 0.001 \\
\hline \multirow[t]{2}{*}{ Emotional support } & Adjusted & Ref. & $-10.0(-13.3,-6.8)$ & 0.000 & $-14.6(-17.9,-11.4)$ & 0.000 \\
\hline & & Ref. & $-10.6(-13.8,-7.4)$ & 0.000 & $-14.0(-17.3,-10.8)$ & 0.000 \\
\hline \multirow[t]{2}{*}{ Respect for patient preferences } & Adjusted & Ref. & $-7.7(-10.1,-5.2)$ & 0.000 & $-18.4(-20.8,-16.0)$ & 0.000 \\
\hline & & Ref. & $-8.0(-10.4,-5.7)$ & 0.000 & $-18.6(-21.0,-16.2)$ & 0.000 \\
\hline \multirow[t]{2}{*}{ Involvement of family and friends } & Adjusted & Ref. & $-11.5(-14.8,-8.2)$ & 0.000 & $-12.3(-15.6,-9.0)$ & 0.000 \\
\hline & & Ref. & $-12.3(-15.6,-8.9)$ & 0.000 & $-11.6(14.9,-8.2)$ & 0.000 \\
\hline \multirow[t]{2}{*}{ Continuity and transition } & Adjusted & Ref. & $-1.1(-4.0,1.8)$ & 0.470 & $-7.0(-9.9,-4.1)$ & 0.000 \\
\hline & & Ref. & $-1.8(-4.7,1.1)$ & 0.218 & $-7.3(-10.2,-4.4)$ & 0.000 \\
\hline \multirow[t]{2}{*}{ Summary score } & Adjusted & Ref. & $-7.8(-9.7,-5.9)$ & 0.000 & $-12.8(-14.7,-10.9)$ & 0.000 \\
\hline & & Ref. & $-8.4(-10.2,-6.5)$ & 0.000 & $-12.6(-14.5,-10.7)$ & 0.000 \\
\hline
\end{tabular}

Note: Covariates in the adjusted model include patient age, gender, self-reported education level, marital status, self-reported health status, length of stay, prior admissions and number of comorbidities, smoking habit, alcohol use, insurance and medical benefit status

Prior studies evaluating the effect of accreditation on patient experience have mostly been observational comparing patient experience scores between accredited and unaccredited hospitals, with little support for accreditation improving patient experience [17, 20-22]. Given these findings, a prior narrative review of the health service accreditation literature by Hinchcliff and colleagues concluded accreditation may target aspects of health care less visible to patients [23]. However, the improving patient experience scores in our study following accreditation suggest accreditation indeed reached the patient sphere. In fact, the domain showing the greatest absolute change over the study period was "respect for patient preferences," which declined (improved) significantly at both T2 and T3. Given the significant resource expenditures and increased staff workload required to facilitate the accreditation process and despite accreditation's often-questioned utility, this study suggests patients may benefit from the extensive effort [9].

This study also provides new understanding of patient experience with care in Asia. Only a few studies to date have evaluated patient experience within an Asian context, identifying different priorities for care than in western contexts [24]. The 2005 THS data presented as a benchmark for our study indicate not only a higher proportion of problems relative to Western contexts, but also different types of problems [3]. Consistent with our study data, the most commonly reported problem in the 2005 THS was "not sufficiently involved in decisions about treatment and care," indicated by $89 \%$ of THS respondents who attended a public hospital and $66 \%$ of our respondents at baseline, more than double the proportion indicating this as a problem in western contexts [3]. Likewise, lack of emotional support from doctors and nurses to discuss fears and anxieties was a key complaint in both the THS and study hospital data, differing from emotional support concerns in western contexts where patients are more likely to indicate difficulty finding someone to talk to about concerns [3]. Chan and colleagues speculate that discrepancies between Hong Kong and western patients' perceptions of care may reflect health care providers "not schooled or conditioned in the patient-centred participatory tradition of care, which per se has been a fairly recent development in the West." [3] Findings from our study suggest the accreditation effort may especially enhance these disparate areas, improving patient perception of involvement in care and emotional support from providers.

Although our study provides compelling evidence of positive effects of accreditation on patient experience, it is not without limitations. First, this study was exploratory research aiming to assess the impact of hospital accreditation on patient experience in one hospital. While we would have preferred to compare multiple hospitals with and without accreditation interventions, only the single case study was feasible and thus results may not be generalizable to other hospitals. Second, given hospital patient experience surveys evaluate patient care 
episodes, we were not able to collect data from the same patients for multiple time points, and thus our data represents three cross-sections. Although we sought to ensure data from the three cross-sections were comparable through identical recruitment procedures, T3 subjects were more likely to report better self-perceived health and comorbidities, which may have influenced raw patient experience scores. However, our adjusted analyses controlling for these covariates confirmed the unadjusted results. We also sought to minimize both recall and response fear bias by recruiting during the inpatient stay but conducting the survey 1 week postdischarge.

\section{Conclusion}

Despite limited evidence supporting its effect on patient outcomes, accreditation continues to thrive as an international industry, and essential and often compulsory quality improvement activity $[9-11,14]$. This study provides initial evidence of the positive potential of the hospital accreditation exercise to enhance patient experience. Moreover, it suggests the quality improvement initiatives associated with accreditation may address areas of concern emphasized by Hong Kong patients, such as involvement in care and emotional support from providers. Further studies should assess the effect of accreditation on patient experience in different settings including both accreditation intervention and non-intervention sites. Moreover, additional studies should investigate the particular interventions related to accreditation that may have influenced patient experience. As hospitals continue to pursue accreditation going forward in spite of limited evidence of other positive effects, they should seek to harness its potential to improve patient experience.

\section{Abbreviations}

ACHS: Australian Council on Healthcare Standards; HN: Hospital Number; ICD-9-CM: International Classification of Diseases, Ninth Revision, Clinical Modification; PPE-15: Picker Patient Experience Questionnaire-15; T1: Time 1 (baseline, 9 months pre-accreditation); T2: Time 2 (three months postaccreditation); T3: Time 3 (fifteen months post-accreditation); THS: Thematic Household Survey; USI: Unique study identification number

\section{Acknowledgements}

Not applicable.

\section{Authors' contributions}

JMJ and WenS planned and designed the study, managed data collection and initial analysis. EBA and WeiS conducted additional analysis. All authors were involved in interpretation of the data. EBA and WeiS drafted the manuscript. JMJ provided critical contributions to the analysis and discussion. All authors read and approved the final manuscript.

\section{Funding}

This work was supported by the Faculty Development Fund through matching grants from the University of Hong Kong Li Ka Shing Faculty of Medicine and the Queen Mary Hospital Charitable Trust. The funders had no role in the design, data collection, or analysis of this study and were not involved in the interpretation of data or in writing the manuscript.

\section{Availability of data and materials}

The (de-identified) datasets generated and analysed during the current study are available from the corresponding author on reasonable request.

\section{Ethics approval and consent to participate}

The Institutional Review Board of the University of Hong Kong/Hospital Authority Hong Kong West Cluster (UW09-435) approved this study. Research staff invited patients to participate and obtained written consent in the hospital, then contacted consented respondents via telephone 1 week post-discharge.

\section{Consent for publication}

Not applicable.

\section{Competing interests}

The authors declare that they have no competing interests.

Received: 14 July 2019 Accepted: 22 August 2019

Published online: 03 September 2019

\section{References}

1. Doyle $C$, Lennox L, Bell D. A systematic review of evidence on the links between patient experience and clinical safety and effectiveness. BMJ Open. 2013:3:e001570

2. Jha AK, Orav EJ, Zheng J, Epstein AM. Patients' perception of hospital care in the United States. N Engl J Med. 2008;359:1921-31.

3. Chan SK, Wong IO, Tin KY, Fung A, Johnston JM, Leung GM. Satisfaction with inpatient care in a population-based Hong Kong Chinese sample. Qual Saf Health Care. 2010;19:173-81.

4. Black N, Jenkinson C. Measuring patients experiences and outcomes. BMJ. 2009:339:202-5.

5. Department of Health. Equity and Excellence: Liberating the NHS. UK. https://webarchive.nationalarchives.gov.uk/20130104175103/http://www.dh. gov.uk/en/Publicationsandstatistics/Publications/ PublicationsPolicyAndGuidance/DH_117353.

6. Isaac T, Zaslavsky AM, Cleary PD, Landon BE. The relationship between patients' perception of care and measures of hospital quality and safety. Health Serv Res. 2010;45:1024-40.

7. Kahn CN, Ault T, Potetz L. Assessing Medicare's hospital pay-forperformance programs and whether they are achieving their goals. Health Aff. 2015;34:1281-8.

8. Beaulieu ND, Epstein AM. National Committee on quality assurance health -plan accreditation: predictors, correlates of performance, and market impact. Med Care. 2002;1:325-37.

9. Brubakk K, Vist GE, Bukholm G, et al. A systematic review of hospital accreditation: the challenges of measuring complex intervention effects. BMC Health Serv Res. 2015;15:280.

10. Braithwaite J, Westbrook J, Pawsey M, Greenfield D, Naylor J, ledema R, Runciman B, Redman S, Jorm C, Robinson M, Nathan S. A prospective, multi-method, multi-disciplinary, multi-level, collaborative, socialorganisational design for researching health sector accreditation. BMC Health Serv Res. 2006;6:113.

11. Flodgren G, Pomey MP, Taber SA, Eccles MP. Effectiveness of external inspection of compliance with standards in improving healthcare organisation behaviour, healthcare professional behaviour or patient outcomes. Cochrane Database of Systematic Reviews. 2011:11. https://www. ncbi.nlm.nih.gov/pubmed/22071861.

12. Cudney $A E$, Reinbold O. JCAHO: responding to quality and safety imperatives. J Healthc Manag. 2002:47:216.

13. Shaw CD. Evaluating accreditation. Int J Qual Health Care. 2003;15:455-6.

14. Greenfield D, Braithwaite J. Health sector accreditation research: a systematic review. Int J Qual Health Care. 2008;20:172-83.

15. Sack C, Lutkes P, Gunther W, Erbel R, Jockel K-H, Holtmann G. Challenging the holy grail of hospital accreditation: a cross sectional study of inpatient satisfaction in the field of cardiology. BMC Health Serv Res. 2010;10:120.

16. Sack C, Scherag A, Lütkes P, Günther W, Jöckel K-H, Holtmann G. Is there an association between hospital accreditation and patient satisfaction with hospital care? A survey of 37000 patients treated by 73 hospitals. Int J Qual Health Care. 2011;23:278-83. 
17. Almasabi $\mathrm{M}$, Yang $\mathrm{H}$, Thomas $\mathrm{S}$. A systematic review of the association between healthcare accreditation and patient satisfaction. World Appl Sci J. 2014;31:1618-23.

18. Chiu A, Seto WH, Lai L. Journey of a Hong Kong public teaching hospital in preparation of hospital accreditation. Hong Kong Med J. 2011;17:231-6.

19. Jenkinson C, Coulter A, Bruster S. The picker patient experience questionnaire: development and validation using data from in-patient surveys in five countries. Int J Qual Health Care. 2002;14:353-8.

20. Jha AK. Accreditation, quality, and making hospital care better. JAMA. 2018; 320:2410-1.

21. Lam MB, Fiqueroa JF, Feyman Y, Reimold KE, Orav EJ, Jha AK. Association between patient outcomes and accreditation in US hospitals: observational study. BMJ. 2018;363:k4011.

22. Al Tehewy M, Salem B, Habil I, El Okda S. Evaluation of accreditation program in non-governmental organizations' health units in Egypt: short -term outcomes. Int J Qual Health Care. 2009;21:183-9.

23. Hinchcliff R, Greenfield D, Moldovan M, Westbrook Jl, Pawsey M, Mumford $\mathrm{V}$, Braithwaite J. Narrative synthesis of health service accreditation literature. BMJ Qual Saf. 2012;21:979-91.

24. Wei J, X-I W, H-b Y, T-b Y. Development of an In-Patient Satisfaction Questionnaire for the Chinese Population. PLoS One. 2015;10:e0144785.

\section{Publisher's Note}

Springer Nature remains neutral with regard to jurisdictional claims in published maps and institutional affiliations.

Ready to submit your research? Choose BMC and benefit from:

- fast, convenient online submission

- thorough peer review by experienced researchers in your field

- rapid publication on acceptance

- support for research data, including large and complex data types

- gold Open Access which fosters wider collaboration and increased citations

- maximum visibility for your research: over $100 \mathrm{M}$ website views per year

At $\mathrm{BMC}$, research is always in progress.

Learn more biomedcentral.com/submissions 